\title{
Academic Stress among Undergraduate Students: Measuring the Effects of Stress Inoculation Techniques
}

\author{
A.O. Busari (Ph.D) \\ Department of Guidance and Counselling, University of Ibadan, Ibadan, Nigeria \\ Email: olanikebusari@yahoo.com
}

\section{Doi:10.5901/mjss.2014.v5n27p599}

\begin{abstract}
The study investigated the Effects of Stress Inoculation Techniques in Fostering Adjustment to Academic Stress among Undergraduate Students of University of Ado Ekiti, Emmanuel Alayande Campus Oyo, Symptoms of stress and various stressors in Academic work of students were identified.480 students participated in this study. Data was collected using Student Academic Stress scale (SASS) Independent samples, t-test statistical analysis was utilized to process the data of the hypotheses tested while simple percentage was used to analyse symptoms of stress and various stress in academic work.Results of the findings indicated that Stress Inoculation Techniques was effective in fostering adjustment to academic stress among undergraduate students. Experimental group were better adjusted to academic stress than the control group. Results also indicated that undergraduates in their second year were better adjusted to academic stress than their first year counterparts. Male participants differ significantly in their level of adjustment to academic stress than the female participants. Again, treatment was effective on participants that attended public secondary schools than those that attended private secondary schools. Implications for lecturers, counselors, and university administrators were also discussed.
\end{abstract}

Keywords: Stress Inoculation, Adjustment, Academic stress, Undergraduates.

\section{Introduction}

Stress has become an important topic in academic circle as well as in our society. Many scholars in the field of behavioural science have carried out extensive research on stress and its outcomes and concluded that the topic needed more attention (Rees and Redfern, 2000; Ellison,2004; Ongori and Agolla, 2008; Agolla, 2009). Stress in academic institutions can have both positive and negative consequences if not well managed (Smith, 2002; Tweedet al., 2004; Stevenson and Harper, 2006). Academic institutions have different work settings compared to non-academic and therefore one would expect the difference in symptoms, causes, and consequences of stress in the two set up (Elfering et al., 2005; Chang and Lu, 2007). It is important to the society that students should learn and acquire the necessary knowledge and skills that will in turn make them contribute positively to the development of the general economy of any nation. However, the intricate academic environment sometimes poses great medical problems to the students' lives (Danna and Griffin, 1999; Dyck, 2001; Grawitch et al., 2007; Ongori,2008) that tend to negate the positive gains that one would expect after completion of University. These scholars assertion needs attention if the needed stress management in university have to be effective. Students' expectations vary with respect to personality and their backgrounds which influences on how individual perceive the environment around him/her. Students at the university have different expectations, goals, and values that they want to fulfill at the university, which is only possible if the students' expectations, goals, and values sre integrated with that of the university (Goodman,1993).

\section{Stress and Academic Stress}

Researchers (Vermunt and Steensman, 2005; Topper,2007; Ussery, 2007; Malach-Pines and Keinan, 2007)have defined stress as the perception of discrepancy between environmental demands (stressors) and individual capacities to fulfill these demands. While researcher(Campbell, 2006) defines stress as the adverse reaction people have to excessive pressure or other types of demands placed on them. Stress occurs when an individual is confronted by a situation that they perceive as overwhelming and cannot cope up with. Academic stress among students have long been researched on, and researchers have identified stressors as too many assignments, competition with other students, failures, lack of pocket money (Fairbrother and Warn, 2003), poor relationships with other students or lecturers, family or problems at home. Institutional (university) level stressors are overcrowded lecture halls, (Ongori, 2007; Awino and Agolla, (2008), 
semester system, and inadequate resources to perform academic work.

Erkutlu and Chafra(2006) for instance opines that, when these events take place, an individual becomes disorganised, disoriented and therefore less able to cope up, thus resulting in stress related health problems.

The pressure to perform well in the examination or test and time allocated makes academic environment very stressful. (Erkutlu and Chafra,2006; Polychronopoulou and Divaris, 2005; Misra and McKean, 2000). This is likely to affect the social relations both within the University and outside (Fairbrother andWarn, 2004) since there is conflict with the social aspect of individual life. This is not the only effect the social relations within or outside the University, but this goes to affect the individual person's life in terms of commitment to achieving the goals. Knowing the causes of students stress will make the University administrator know how to monitor and control the stress factors that are responsible for the students stress. Scholars (Ornelas and Kleiner, 2003;Jaramillo et al., 2004; Verment and Steesma, 2005;Ongori, 2007; Topper, 2007; Ongori and Agolla, 2008;Agolla, 2009) for instance identified the symptoms and the causes of stress in work environments as sitting for along period of time, poor work performance, poor interpersonal relationship, inadequate or lack of resources, inadequate time to perform particular assignments, poor working conditions, overcrowded work stations, excessive paperwork, and many others. Whereas these factors have been found to be responsible for stress, it is worth noting that in order to minimize the stress among students, the University administrators must develop appropriate strategies that will enable them to detect in advance the symptoms and causes of the stress.

Researchers (Malach-Pines and Keinan, 2007; Ongori,2007; Ongori and Agolla, 2008; Agolla, 2009) have long identified stress symptoms as lack of energy, taking over the counter medication, high blood pressure, feeling depresssed, increase in appetite, trouble concentrating ,restlessness, tensions and anxiety among others. An individual experiencing one of these factors is likely to be a victim of stress. Although this may also depend on how the individual appraises the situation, and how resilient is the person. While the negative effects of stress on an individual may vary considerably from one student based on their previous encounter with situations and the resilient of the individual student. In their findings (Jaramilloet al., 2005; Stevenson and Harper, 2006) point out that ,the perception of the individual determines whether or not the stressor has a detrimental effect; that is whether itcauses physical or psychological symptoms of stress in the individual. Earlier study by Siegrist (1998) also indicated a close link between high amounts of occupational stress and ill health. This means that deterioration in health of the individual is likely to affect the individual performance. In a higher learning institution such as University (Smith et al., 2000) where the demand placed on students is based on deadlines and pressure for excelling in tests or examination, students are likely to be the victims of stress.

The argument is that, students stress has not gained much attention since most scholars were preoccupied with the conventional work related stress as opposed to academic students stress.

Institutions world -wide have not taken serious steps to find out the health of students, this could be attributed to the fact that students who stay at the university is based on short period, and therefore their stress have little direct impact on the activities or operations of the institution. Another reason why little have been done on students stress could be due to the fact that students' presence in the institution have no direct relationship to the quality of education they get. It is argue that, unless the university puts appropriate measures that take care of well- being of the students, the student's health may compromise the quality of education they are supposed to get(Daniels and Harris, 2000; Smith et al., 2000; Finlayson,2003). Gibbons and Gibbons (2007) and McCarty et al.(2007) have carried out extensive research on stress and found out that, stress is associated with how an individual appraises situations and the coping strategies adopted.

The motivation for this research is that, there have been reported cases of stress among students that has resulted in loss of lives. The causes for such actions are not known since the victims of stress are never present to tell their stories. Although the counseling centre within the University do keep records of students who seek help from them, but this alone has failed to help identify strongly the causes and coping mechanisms. Again ,there have been cases of reported violence among some students, and reported cases of poor lecture attendance. The future of any nation lies heavily on the young people since they are the tomorrow's leaders; therefore, it is important to identify the causes, symptoms, and the consequences of stress on students. This will help the university administrators to come up with the best strategies to enable the students to cope up with these stressors while pursuing their academic careers. The negative effect of stress on students is likely to pose challenge to the individual students, their colleagues, and the institution as a whole (Siegrist, 1998; Cartwright and Boyes, 2000). The outcome associated with stress such as suicide, violence, and drug abuse among others have been witnessed in the institution often, and are worthpaying attention to. Stress poses a great threat to quality Sof life for students (Danna and Griffin, 1999; Dyck, 2001).

Students interact amongst themselves as well as with their lecturers, therefore unduly stressed and unhappy students will reflect this in the process of the engagement that may result in conflict (Ongori, 2007) other researchers have been assessing academic stress among categories of students using descriptive method. This present study intends to prevent academic stress by utilizing stress inoculation techniques to foster adjustment among university 
undergraduate students.

\subsection{Stress Inoculation Techniques (SIT)}

Stress inoculation techniques could be seen as a treatment package incorporating elements and adaptations of other anxiety reduction methods. These methods are used to assist anxious persons to change self-defeating thoughts and to enable them tolerate and cope with being in the presence of the anxiety situation until the anxiety diminishes.

Donald Meichenbaum (1979) developed a cognitive restructuring procedure called Stress - Inoculation Training (SIT),Meichenbaums SIT is described here as a prototype of the cognitive restructuring approaches since it incorporate elements of the other cognitive approaches along with other treatments that are cognitive in nature.

Stress inoculation training is described by Meichenbaum as a three-phase therapy process. The phases are: conceptualization, skill acquisition and rehearsal, application and follow through-The initial stage which is conceptualization phase is on establishing a collaborative relationship with clients and on helping them to better understand the nature of stress and its effect on emotion and performance and to reconceptualize it in transactional terms.

In phase 1, the participants is provided with a conceptualization of the problem. This enables the participants to realize the connection between thoughts, emotion, and behaviour. It is not really the situation that causes the stress, but what the person think and say to themselves about the situation. The goal of phase 1 is to have the participants realize this connection between thinking, catastrophic thoughts and self-defeating stress they exhibit.

The second phase is called skills acquisitionand rehearsal during which clients develop and rehearse a variety of coping skills, primarily within the clinic and gradually in vivo.

Here clients are enlisted as collaborators in appreciating and removing such inhibitory factors.

Phase II involves developing and testing new things to do and to think that can prevent and or counter stess response. These new things include learning relaxation techniques that could be used to help an individual prepare for and cope with stress provoking situation. Also new self-statements and thoughts about situations could be tried and rehearsed. The participants develop statements to say to themselves prior to meeting the stress "no negative thoughts". Then when actually in the situation, another set of self-statements can be used to keep the person on task and use coping skills. Once the stress has passed, the person needs to reinforce him/herself for having tolerated it and got through it.

The third phase is called application and follow-through which begin once the person has developed and tried out a series of new self -statements and coping skills. This phase is the actual use of these skills in stressful situations. Here the full package of new skills, thinking, self-statements and relaxation is put to use to enable the person to begin tolerating stressful situations.

Other procedures might be enlisted to facilitate this process. For example, Meichebaum (1979) would encourage participants to use a variant of systematic desensitization as described by Goldfred(1982) in which anxiety hierarchy scenes are visualized with the person coping with an attempt to reduce the felt stress. These scenes might actually involve the person visualizing himself being in the situation making coping self-statement and being able to tolerate it. In other words, this combines elements of systematic desensitization and covert or imaginal self-modeling, along with changes in self- statements.

\subsection{Objectives}

The general objective of this study is to assess the effect of Stress Inoculation Techniques in fostering adjustment to academic stress among undergraduates students.

I. to determine the difference in the adjustment level of participants in the experimental and those in the control group.

II. To find out the difference in the level of adjustment of male and female participants exposed to stress inoculation techniques.

III. To ascertain the difference in the level of adjustment of undergraduate students who attended private and those who attended public secondary schools treated with stress inoculation techniques.

IV. To measure the difference in the level of adjustment of first and second year undergraduate students exposed to stress inoculation techniques. 


\subsection{Hypotheses}

The following null hypotheses were formulated and tested at 0.05 level of significant

Ho1: There is no significant difference in the level of adjustment to academic stress of participants in the experimental group and those in the control group.

Ho2: There is no significant difference in the level of adjustment of male and female undergraduate students exposed to stress inoculation techniques.

Hoз: There is no significant difference in the level of adjustment of undergraduate students who attended private and those who attended public secondary schools treated with stress inoculation techniques.

Ho4:There is no significant difference in the level of adjustment of first and second year undergraduate students exposed to stress inoculation techniques.

\section{Methodology}

\subsection{Design}

The design adopted for this study was pre-post experimental design.

\subsection{Participants}

The participants were drawn from undergraduate students of the University of Ado Ekiti Oyo Campus 600 formerly self administered questionnaires were given to a population of 600 undergraduatestudents, out of this, 480 questionnaires were duly completed andreturned, giving return rate of $80 \%$. This return rate was consideredsufficient for this type of research (McCarty et al., 2007; Saunders and Thomhil, 2007). The participants consisted of 290 femaleand 190 male students. Of the participants 270 were year 1 and 210 year 2 students. 208 attended private secondary schools while 272 attended public secondary schools.

\subsection{Sampling}

Sampling method applied in this study was a convenient random sampling. The participants were addressed before the questionnaires were administered during lecture time, and were informed of the purpose of the research and the importance of their participation in this project. They were given 30 minutes to complete the questionnaire. This time was found to be appropriate given that the questionnaire was only a page and a half. This procedure was also found to be appropriate since it is easier for the students to complete the questionnaire and return the same within the lecture time. The questionnaires were administered to the students of the faculty of Education and students from other faculties within the Oyo Campus of University of Ado-Ekiti.

\subsection{Instrument}

\subsubsection{Student Academic Stress Scale (SASS)}

Busari (2011) constructed and validated Student Academic Stress Scale (SASS).

The SASS is a self reported scale through which individual students describes his areas of stress regarding his/her academic work, according to the extent to which he/she is willing to disclose them. It is essentially a precise and timesaving method providing information about the major concerns of individual students or group. The SASS is a measure of stress response developed specifically for quantifying stress on university students in the stress response domains, physiological, behavioural, cognitive and affective. This scale has two sub-sections. Section A consists of demographic information such as sex, course, level, the type of secondary school attended, age, while section B consist of 50 items in various domain of academic stress.

Respondents rate how much of the time they experience symptoms on a 5-point likert scale with the anchors none of the time (1) A little of the time (2) some of the time (3) most of the time (4) and all of the time (5) items are summed for subscale scores and subscales are summed for a total of SASS stress response score. Higher scores indicate a greater stress response. The SASS produced excellent reliability using cronbach alpha for the overall SASS scale and subscales. And all alphas were above .80. This indicates that the SASS is a reliable measure of academic stress responses. 


\subsection{Procedure}

After responding to Stress Scale which was used as a screening device .Participants in this study completed Student Academic Stress Scale (SASS) by Busari (2011) during the week prior to treatment, the last week of the treatment programme. Control group participants also completed the questionnaire during the week prior to the start of the treatment programme and during the last week of the programme. SASS is a self rating instrument, which measures domain of academic stress. The scale consist of 50 items thatask subjects to describe which academic area gives them stress. Psychotherapeutic exposure was then provided over eight-one hour sessions for the experimental group only.

\subsection{Treatment}

480 undergraduate students participated in eight one-hour session which held once a week, for eight consecutive weeks. The programme consisted of eight basic components, presentation of a conceptual framework, identification of stress responsiveness of individual participants, identification of relations of stress to anxiety, and well-being , identification of influence of stress to academic work, developing and testing new skills to counter the stress responses, application and practice of new acquired skills to manage stress domains and review of previous sessions activities and administration of post-test instrument.

During the first session pre-test assessment was administered after which participants introduced themselves to each other and definitions of stress inoculation, incidence of stress, causes of stress and effects of stress on students and their academic work were discussed.

Each participant was then asked to identify specific situations which were stressful to them as it affects their academic work. Situations identified include financial problem, academic work loads, inadequate resources, low motivation, poor performance in academic, continuous poor performance, overcrowded lecture hall etc. participants were given an overview of the coping skills to be taught during the next session and were informed that in order for the techniques to be helpful daily practice between sessions was necessary.

The second session focused on the identification of stress responsiveness of individual participants. The therapists and the participants discussed personal problems which constitutes academic stress.

During the third session, participants were presented with the identifications of relations of stress effect to anxiety and well-being. The therapists and the participants discussed Meichenbaum(1979) Stress inoculation training (SIT).Participants were provided with the information that a stress reactions takes place in stages. Some of these stages include, preparing for stressor, confronting a stressor, being overwhelmed for having coped, and self reinforcement for having coped .Participants were trained that stress reactions are not as automatic as previously thought and they can intervene in the middle of the reaction with various learned techniques. Self-reports of stress are to some extent affected by a general personality disposition to stress more or less independent of the content of the specific stress. Thus in this session participants were taught in identification of unrealistic beliefs, negative self statements and stress physical arousal relating to participants academic pursuits.

During the fourth session identification of influence of stress to academic work were reviewed and participants discussed how these influence contributed to their poor academic performance and their general wellbeing. They were taught how to recognize maladaptive thoughts that impiches academic work.

In the fifth session participants were presented with the role of self- statements in emotions and behavior. The idea that emotions are not the direct result of events, but area product of the view an individual takes of them was presented and personal responsibility for stress was emphasized. They were also trained on how to modify their stressful thoughts by replacing them with positive self- statements.

The sixth session focused on developing and testing new things to counter stressful thoughts. The therapists and the participants discussed how to develop and test new things to do and think on, that can prevent and/or counter stressful responses. These new things include relaxation training to develop statements to say to themselves prior to meeting the stressor.

The seventh and eight sessions focused on rehearsal and application of treatment conditions. Participants were taught how to develop "Stress Scripts". The stress scripts provide cognitive, emotional and behavioural direction for reactions to stress situations including worry. Participants identified their thought, feeling and behavior to help them cope with the situations more constructively. The reactions were then rehearsed through role playing and imagery. The post test instruments were them administered to the treatment and the control groups. 


\subsection{Data Analysis}

To test the hypotheses of this study, independent samples t-test was used. The independent samples t-test is used when researchers wants to examine the mean difference between two exclusive or independent groups (Hyman \& Sierra 2010). Independent samples test was performed using SPSS version 15.0. Symptoms of stress among students, sources of stressors in academic work and major source of stress were processed using simple percentage.

\section{Results}

Table 1: Symptoms of Stress Among Students N=480

\begin{tabular}{|l|c|}
\hline Symptoms of stress & $\begin{array}{c}\text { Most of the time } \\
\text { and All the time }\end{array}$ \\
\hline Experience, anxiety or nervous indigestion & $92 \%$ \\
\hline People at home or school make me feel anxious & $80 \%$ \\
\hline I eat, drink or smoke in response to anxiety producing situations & $40 \%$ \\
\hline $\begin{array}{l}\text { I feel tense, experience pain in the neck or shoulders, and suffer form migraine headaches } \\
\text { or have difficulty in breathing }\end{array}$ & $79 \%$ \\
\hline $\begin{array}{l}\text { I can't stop thinking about my concerns at night or on weekends long enough to feel } \\
\text { relaxes and refreshed the next day }\end{array}$ & $88 \%$ \\
\hline I have trouble concentrating on what I'm doing because l'm worrying about otherthings & $93 \%$ \\
\hline I take over the counter medications or prescription drugs to relax & $18 \%$ \\
\hline
\end{tabular}

Table 2: Sources of Stressors in Academic Work of Student N=480

\begin{tabular}{|l|c|}
\hline Variables & Most of the time and all of the time \\
\hline Continuous poor performance & $58 \%$ \\
\hline Unfair treatment by boyfriend/girlfriend & $37 \%$ \\
\hline Workload & $86 \%$ \\
\hline Inadequate resources to do assignments & $72 \%$ \\
\hline Uncertainty about getting job after graduating & $56 \%$ \\
\hline Competition with fellow students & $37 \%$ \\
\hline Overcrowded lecture halls & $60 \%$ \\
\hline High expectations from my parents & $53 \%$ \\
\hline Not attending lectures & $45 \%$ \\
\hline Conflict with my fellow students & $23 \%$ \\
\hline Poor performances & $70 \%$ \\
\hline Low motivation & $74 \%$ \\
\hline Conflict with my lecturers & $27 \%$ \\
\hline
\end{tabular}

Table 3: Name one Major Source of your Stress N=480

\begin{tabular}{|l|c|c|}
\hline Items & No & Percentage \\
\hline Academic overload e.g. assignments, semester, test & 202 & $42 \%$ \\
\hline Academic performance & 90 & $18.8 \%$ \\
\hline Financial & 49 & $10.2 \%$ \\
\hline Fear of failure & 48 & $10 \%$ \\
\hline Inadequate resources e.g. computers, books, lecturers & 43 & $9 \%$ \\
\hline Fear of getting job & 19 & $3.9 \%$ \\
\hline Overcrowded lecture halls & 12 & $2.5 \%$ \\
\hline Relationship withy girl/boyfriend & 9 & $1.9 \%$ \\
\hline Family/academic life & 8 & $1.7 \%$ \\
\hline
\end{tabular}


Table 4: t-test Comparison of Level of Adjustment to Academic Stress between Participants exposed to Treatment and the Control Group

\begin{tabular}{|l|c|c|c|c|c|}
\hline Variables & $\mathrm{N}$ & $\mathrm{X}$ & $\mathrm{SD}$ & $\mathrm{T}$ & $\mathrm{Df}$ \\
\cline { 1 - 5 } Stress Inoculation Techniques & 480 & 24.27 & 7.13 & \multirow{2}{*}{2.51} & \multirow{2}{*}{558} \\
\hline Control Group & 80 & 22.18 & 5.63 & & \\
\hline
\end{tabular}

Table 4, present the difference in the adjustment level of participants between the treatment and the control group. As seen in table 4 there is a significant difference between participants in the treatment and those in the control group. With reference to the mean scores, the treatment group scored higher. The implication is that the participants in the treatment group are better adjusted to academic stress than the control group.

Table 5: t-test Comparison of Level of Adjustment to Academic Stress of Male and Female Undergraduate Students Exposed to Stress Inoculation Techniques

\begin{tabular}{|l|c|c|c|c|c|}
\hline Gender & $\mathrm{N}$ & $\mathrm{X}$ & $\mathrm{SD}$ & $\mathrm{T}$ & $\mathrm{Df}$ \\
\hline Males & 190 & 46.13 & 11.51 & \multirow{2}{*}{2.07} & \multirow{2}{*}{478} \\
\cline { 1 - 4 } Females & 290 & 45.05 & 10.22 & & \\
\hline
\end{tabular}

Table 5presents the difference in the level of adjustment between males and females exposed to treatment. As seen in the table, there is a significant difference between the male and female respondents. With reference to the mean scores, male respondents scored higher. The indication is that male undergraduate students were better adjusted to academic stress, as high means-score indicates better adjustment.

Table 6: t-test Comparison of Level of Adjustment to Academic Stress of Year 1 and Year 2 Undergraduate Students Exposed to Stress Inoculation Techniques

\begin{tabular}{|l|c|c|c|c|c|}
\hline Academic level & $\mathbf{N}$ & $\mathbf{X}$ & SD & T & Df \\
\cline { 1 - 4 } Year 1 & 270 & 25.77 & 7.14 & \multirow{2}{*}{5.79} & \multirow{2}{*}{478} \\
\hline
\end{tabular}

As shown in table 6, the difference in the level of adjustment between year 1 and year 2 undergraduate students indicates that there is a significant difference between the fresh and stale student respondents. With reference to mean scores, year 2 respondents scored higher, since high means-score here indicates better adjustment, it means that year 2 students were better adjusted to academic stress.

Table 7: t-test Comparison of Level of Adjustment to Academic Stress of Undergraduate Students with Private and those with Public Secondary Education Exposed to Stress Inoculation Techniques

\begin{tabular}{|l|c|c|c|c|c|}
\hline Type of secondary school attended & N & X & SD & T & Df \\
\cline { 1 - 4 } Private & 208 & 24.32 & 6.92 & \multirow{2}{*}{2.90} & \multirow{2}{*}{478} \\
\hline Public & 272 & 25.64 & 7.24 & & \\
\hline
\end{tabular}

Table 7, presents the difference in level of adjustment to academic stress of undergraduate students with private and those with public secondary education. The compared means outcome for undergraduate secondary education. The compared means outcome for undergraduates that attended private and those that attended public secondary schools were juxtaposed as could be inferred from the table .Undergraduate students who attended public secondary school exhibited better level of adjustment to academic stress. High means-scores in this case indicates better adjustment.

\section{Discussion of Results}

In Table I the analysis was done by calculating the percentage of respondents who gave a high rating symptoms on SASS scale. The result indicates hat students do experience stress related symptoms as shown in Table 1. The compounded result of the responses indicates that (92\%) students have experienced anxiety, or nervous or having 
indigestion problems more than once at the University. The finding is consistent to earlier studies (Cohen and Single, 2001; Ongori, 2007; Topper, 2007; Agolla, 2009). The finding reflects that, most of the students are experiencing stress in their daily academic activities. Students (86\%) pointed out that, people at home or campus makes them feel anxious about their daily lives. This finding is in agreement with the study of (Fairbrother and Warn, 2003) that identified conflicts at home and work environment as one source of individual stress. This indicates that students experience a lot of pressure from home or cam-pus which impact either negatively or positively on their daily lives.

In response to eating, drinking or smoking, (40\%) of the students indicated that they engaged in such activities in response to anxiety producing situations. This finding is consistent with the earlier finding sof the scholars (Cohen and Single, 2001; Stevenson and Harper, 2006; McCarty et al., 2007) which revealed that ,people tend to resort to drinking as coping strategies whenever confronted with complex situations in their lives.

While over the counter medication is the lowest among the students. Students also indicate that they often or sometimes feel tense, experience pain in the neck or shoulders, and suffer from migraine headaches, or have difficulty in breathing. This was indicated by $(79 \%)$ of the students who responded to the symptoms of stress that they have experienced. This is consistent with the most findings on stress (McCarty et al., 2007; Ongori,2007; Agolla, 2009). When asked to indicate whether they have stopped thinking of their concerns at night or weekends long enough to feel relaxed and refreshed the next day, (88\%) of the students indicated that they often or sometimes do experience such symptoms. This finding is consistent with earlier studies (Ongori, 2007; Topper,2007; Agolla, 2009). Students (93\%) indicated that they have trouble concentrating on what they are doing, because they worry about other things. This is in line with the other studies (Elfering et al., 2005; Agolla, 2008) on stress which also identified trouble concentrating as a symptom. On the question of whether they are involved in taking over-the-counter medications or prescription drugs to relax, (18\%) indicated that they have been involved in taking over- the- counter medications or prescription drugs to relax. This is consistent with the finding by (Agolla, 2009). It also reveals that the students do not take to drugs or alcohol as coping strategies when stressed

However, the second part of the scale was to elicit their responses with regard to what students consider sources of their stress while on campus. This result is presented in Table 2. The result indicates that (58\%) of the students view continuous poor performance as stressful. This finding is consistent with earlier studies (Dua, 1994; Fairbrother and Warn, 2003;Erkutlu and Chafra, 2006; Topper, 2007). Whether their relationships with fiancés or fiancées are causing stress,(37\%) of the students agreed. On the question regarding academic workload, (86\%) of the students agreed with the statement that academic workload is stressful. This finding is consistent with earlier findings (Fairbrother and Warn,2003; Polychronopoulou and Davaris, 2005; Stevenson and Harper, 2006; Ongori and Agolla, 2008; Agolla,2009).

Inadequate resources to do assignments such computers and books were rated by (72\%) of the students as stressful. The students also pointed out that their stress is exacerbated by the inadequate resources which could not meet their needs. This was consistent with the findings of (Murphy, 1996; Misra and McKean, 2000; Awino and Agolla, 2008; Agolla, 2009). Uncertainty about getting job after graduating was rated by (56\%) of the students who indicated that their prospects of getting a job after graduating is stressful. This finding is in line with that of (Kaczynski, 2004) that identified the causes of stress among people as uncertainty about the future.

Competition with fellow students (37\%) of the participants agreed with the statement that it is causing stress, This is inconsistent with earlier studies (Ongori, 2007; Ongoriand Agolla, 2008) that identified competition as a source of stress among employees in organisations. Students(60\%) rated overcrowded lecture halls as stressful, since they have to take their lectures while standing outside or inside due to shortages of seats or accommodation. This finding is consistent with earlier studies (Ongori, 2007;Topper, 2007; McCarty et al., 2007; Awino and Agolla,2008; Agolla, 2009) which revealed that overcrowded lecture halls are causing students a serious problem as some have to take their lectures while standing due to lack of seats or outside because there is no space inside the lecture halls.

Students (53\%) rated high expectations from parents, relatives and friends stressful. This finding is consistent to earlier findings (Polychronopoulou and Divaris,2005; Ongori, 2007; Topper, 2007; Agolla, 2009) that identified the expectation from parents, friends or relatives as one of the causes of the stress to an individual.

On the question of whether or not attending lectures will stress them, (45\%) of the students agreed strongly,70\% of the students agreed that poor performance is a source of stress. Low or lack of motivation among the students has been rated by(74\%) of the respondents who stated that is stressful . This is consistent with most of the stress studies(Kaczynski, 2004; McCarty et al., 2007). Conflict with lecturers was not seen as creating stress among students as only $27 \%$ agreed to that statement. This is inconsistent to studies on stress (Goodman, 1993; Murphy and Archer, 1996;LeRoy, 1988; Ongori, 2007; Topper, 2007; Ongori, 2008;Agolla, 2009). This indicates that there is cordial relationship between students and their lecturers which is good for learning environment. 
In order to find out the major causes of students stress ,the students were restricted to one open ended question that required them to list only one major source of stress responsible for their academic stress. The result of the open ended question is presented in Table 3. Thematic analysis (Table 3) reveals that students' stressors are academic workload, academic performance, fear of failing, (Awino and Agolla, 2008), inadequate resources ,financial problems, overcrowded lecture halls, poor relationship with girlfriend / boyfriend, family / academic life conflicts and fear of getting job after completing studies. Students indicated that academic workload is due to(Misra and McKean, 2000) short semester coupled with too many assignments, tests and preparation for the final semester examination. They cited too much work to be accomplished within short time that leaves them with no time to enjoy their social life. This is consistent with other studies (Fairbrother and Warn, 2003; Ongori, 2007;McCarty, Zhao and Garland, 2007; Agolla, 2009).

Academic performance and fear of failing are other stressors that are of concern to the students' health life. This is consistent to earlier studies (Polychronopoulouand Divaris, 2005; Topper, 2007; Trares and Kohler,2007) that identified fear of failing or poor performance as stressful. Continuous poor academic performance and expectation from family or friends have been cited as some of the problems that they face in their daily academic life at the campus. On the other hand students also indicated inadequate resources and financial matters as stressors. This findings is consistent with earlier studies(Fairbrother and Warn, 2003; Ornelas and Kleiner, 2003).

Inadequate resources such as computers, overcrowded lecture halls, lecturers, and text books were mentioned since their availability or in availability leads to success or failure in academic pursuits. Whereas other students indicated that they are affected by their relationship with their spouses. These findings are consistent with the earlier findings of scholars (Misra and McKean, 2000;Polychronopoulou and Divaris, 2005; Awino and Agolla,2008) who identified academic stressors among undergraduate dental students as too much amount of class work and lack of time to do assignment.

The result of this study provide support for the use of stress Inoculation Technique(SIT) in the management of academic stress among the undergraduate students as seen in Table 4. The data showed improvement in the level of adjustment of the participants in the treatment group compared to their counterparts in the control group. The result following the treatment programme showed that the group which was exposed to experimental conditions indicated a mean score of 24.27 as against the control group with a mean score of 22.18. This finding corroborates with the findings of Meichenbaun 1979 which found the use of Stress Inoculation Training to be effective with clinical population.

The results of hypothesis two as indicated in table 5 proved that indeed there was significant difference in the level of adjustment between males and females undergraduate treated with stress inoculation techniques. Male undergraduate students exhibited better adjustment than their female counterparts to academic stress. This finding lend support to result of earlier studies conducted by Geatley et al (2007) which focused that gender differences exist in the experience of stress. It also corroborates the findings of Busari (2000) which reported test anxiety reduction of male students after exposure to stress inoculation training techniques. This finding is not surprising considering the fact that female students tend to be more emotional and sensitive towards what is happening in their surroundings.

Again, table 6 shows that there is a significant difference in the level of adjustment to academic stress between year 1 and year 2 undergraduate students in the treatment programme. The reason for this finding might be related to the fact that when students resumed newly to higher institutions of learning, they are confronted with enormous problems of registration, accommodation, and various intra and interpersonal concerns. The problem of transition from home to school and from dependent to independent might pose adjustment problems on the part of the new students.

Table 7, revealed that undergraduate students with public secondary education exhibited better level of adjustment to academic stress than their counterparts with private secondary education background after treated with stress inoculation techniques. The reason for this result might be because those undergraduate students who attended public secondary schools were used to stressful situations such as inadequate resources, overcrowded classrooms, financial problems, low motivation etc which may be strange or alien to those participants with private secondary education. Overall, stress inoculation techniques has been shown to be effective in fostering adjustment to academic stress.

\section{Conclusions and Implications}

From these findings, the results clearly show that students experience stress in various aspects of academic work. The symptoms identified are anxiety, nervousness, indigestion, endless worries, tense ,pain in the neck or shoulders and people at home or school. While these symptoms do not tell the cases that have already lost control, it is important to note that they are hampering students' ways of academic life. Stresshas been associated with the outcomes such as suicides ,violent behaviour, or even social withdrawals and the need to address issues should be seen as urgent. This is consistent with the spate of violence amongst the university students. 
Again, the results indicated that stress inoculation Techniques is an effective method of fostering adjustment to academic stress among university students.

The implication of this finding is that the university management need to address the above issues raised by the students in order to manage the academic environment conducive for learning. Indeed poor performance and continuous poor performance in tests or examinations can frustrate students and may even (Smith,2002; Tweed et al., 2004; Stevenson and Harper, 2006 Busari and Uwakwe 2001)leave other students with no options but to experience depersonalisation and sometimes to withdraw from the campus (Ongori, 2007). This can lead other students to vent anger at their colleagues or even on girl/ boy friends.

Some students were so specific and did mention course, such as General Education Studies (GES) as heaping too much workload on them, while in real sense these courses mean absolutely nothing to their careers. University should employ more qualified lecturers to alleviate the staff shortage that always lead to overcrowded lecture halls. Since most lecturers encourage students to make use of internet facilities to carry out their research, it is important that there should be adequate computer stations to accommodate students to avoid failure to submit their assignments in time. University should also consider offering services such time management to help students manage their time wisely since this will help them to balance family / academic life, as effective time management seem to lower academic stress.

\subsection{Limitations of the study}

This study adopted convenient sample to select its participants thus making generalization questionable. The university where the research was carried out also has its peculiar situation of being a campus inside college of education thus creating a lot of stress for the undergraduate students.

The researcher therefore recommend that future research should extend their studies to compare academic stress level at federal, state and private universities to validate the current findings. Also other therapeutic interventions different from stress inoculation techniques could be employed to reduce academic stress of university and other students.

\section{References}

Agolla JE (2009) "Occupational Stress among Police Officers": Thecase of Botswana Police service, Res. J. Bus. Manage. 2 (1): 25-35.

Awino JO, Agolla JE (2008) A Quest for Sustainable Quality AssuranceMeasurement for Universities: Case of Study of the University ofBotswana, Educ. Res. Rev. 3 (6): 213-218.

Busari A.O. (2000). Stress Inoculation Training and Self-Statements Monitoring Techniques on the Reduction of Test Anxiety among Adolescent Underachievers in Ibadan Metropolis. An Unpublished Ph.D Thesis, Department of Guidance and Counselling University of Ibadan

Busari and Uwakwe (2001): The Effect of Stress Inoculation Training Technique in the Management of Worry As a Self Handicapping Strategy in Intellectual Performance, Nigerian Journal of Emotional Psychology 3: 6-12.

Busari, A.O. (2011). Validation of Student Academic Stress Scale (SASS).European Journal of Social Sciences 21(1) .94 -105.

Cartwright S, Boyes RF (2000). Taking the pulse of executive health inthe UK. Acad. Manage. Exec. 14(2): 16-24.

Chang K, Lu L (2007). Characteristics of organisational culture,stressors and wellbeing: The case of Taiwanese organisations, J.Manage. Psychol. 22 (6): 549-568.

Cohen J, Single LE (2001). An examination of the perceived impact offlexible work arrangement on professional opportunities in publicaccounting. J. Bus. Ethics 32 (4): 317-9.

Daniels K, Harris C (2000). Work, well being and performance, Occup.Med.,50(5): 304-349.

Danna K, Griffin RW (1999). Health and well being in the workplace: areview and synthesis of the literature, J. Manage., (25) 357.

Dua JK (1994). Job Stressors and Their Effects on Physical Health,Emotional Health, and Job Satisfaction in a University, J. Educ.Admin. 32 (1): 59-78.

Dyck D (2001). "The toxic workplace", Benefits Canada, 25 (3) 52.Elfering A, Grebner S, Semmer NK, Kaier-Freiburghaus D, LauperDelPonte S, Witschi I (2005). Chronic job stressors and job control:effects on event-related coping success and well-being, J. Occup.

Ellison KW (2004). Stress and the Police Officer, 2nd ed., Charles C. Thomas Publishers, Springfield, IL, 71-86.

Erkutlu HV, Chafra J (2006). Relationship between leadership powerbases and job stress of subordinates: example from boutique hotels,Manage. Res. News 29(5): 285-297.

Fairbrother K, Warn J (2003). Workplace Dimensions, Stress and JobSatisfaction, J. Managerial Psychol. 18(1): 8-21.

Finlayson M (2003). Improving the wellbeing of teachers in Scotland,Scott. Educ. J., 87(1): 18-19.

Gibbons RM, Gibbons B (2007) Occupational stress in chefprofessional, Int. J. Contemp. Hospitality Management, (19): 32-42.

Goodman ED (1993). How to handle the stress of being a student.Imprint, 40: 43.

Grawitch MJ, Trares S, Kohler JM (2007), Healthy Workplace Practicesand Employee Outcome, Int. J. Stress Manage. 14(3): 275-293.

Jaramillo F, Nixon R, Sams D (2005). The effect of law enforcement stress on organisational commitment, Policing: Int. J. Police 
Strateg.Manage. 28(2): 321-336.

Johns N, Menzel JP ( 1999). "If you can't stand heat"...kitchen violenceand the culinary art", Hospitality Manage. (18): 99-109.

LeRoy A (1988). How to survive a non traditional nursing student.Imprint, 35 (2): 73-86.

Malach-Pines A, Keinan G (2007). Stress and burnout in Israel policeofficers during Palestinian uprising (intifada), Int. J. Stress Manage.,14: 160-174.

McCarty WP, Zhao JS, Garland BE (2007). Occupational stress andburnout between male and female police officers. Are there anygender differences? Policing: Int. J. Police Strateg. Manage. 30(4):672-691.

Misra R, McKean M (2000).College Students' Academic Stress and itsRelation to their anxiety, time management, and leisure Satisfaction,Am. J. Health Stud. 16(1): 41-51.

Murphy MC, Archer J (1996). Stressors on the college campus: Acomparison of 1985-1993, J. Coll. Stud. Dev. 37(1): 20-28.

Ongori H (2008) Organisational Conflicts and its Effects on OrganisationPerformance, Res. J. Bus. Manage. 2 (1): 16-24.

Ongori H, Agolla JE (2008) "Occupational Stress in Organisations andlts Effects on Organisational Performance, J. Manage. Res. 8(3):123-135.

Ongori H. (2007). A review of the literature on employee turnover, Afri.J. Bus. Manage., 1(3): 49-54.

Ornelas S, Kleiner BH (2003). New Development in Managing JobRelated Stress, Journal of Equal Opportunities International, 2 (5):6470.

Polychronopoulou A, Divaris K (2005). Perceived Sources of Stress Among Greek Dental Students, J. Dent. Educ., 69 (6): $687-692$.

Rees CJ, Redfern D (2000). Recognising the perceived causes ofstress - a training and development perspective, Ind. and Commer.Train. 32(4): 120-127.

Saunders ML, Thornhil A (2007). Research Methods for BusinessStudents. 4th Edn., Pearson Education Limited, ISBN: 0-273-70148-7.

Siegrist J (1998). "Adverse health effects of effort-reward imbalance atwork: theory, empirical support, and implications for prevention", inCooper, C.L. (Ed.), Theories of Organisational Stress, OxfordUniversity Press, New York, NY, 190-204.

Smith A (2002)."The scale of perceived occupational stress", Occup.Med. (50): 294-8.

Smith A, Johal S, Wadsworth E, Smith GD, Peters T (2000). The Scaleof Occupational Stress: The Bristol Stress and Health at work study,HSE Books, Sudbury.

Stevenson A, Harper S (2006). Workplace stress and the student learning experience, Qual. Assur. Educ., 14(2): 167-178.

Topper EF (2007). Stress in the library workplace, New Library World,(11 / 12): 561-564.

Tweed RG, White K, Lehman DR (2004). Culture, stress, and coping.Internally and externally- targeted control strategies of EuropeanCanadians, East Asian Canadians, and Japanese, J. Cross Cult.Psychol., (35) 652-68.

Vermunt R, Steensma H (2005). How can justice be used to managestress in organisations? In J. Greenberg and J.A. Colquitt (Ed.). 